\title{
Comparison between Soil-Water Characteristic Curves based on filter paper method and grain-size distribution/volume-mass prediction: An evaluation of input data stemmed from hydrometer and Cilas grain-size analyser.
}

\author{
Marcos Felipe da Silva André ${ }^{1, *}$ and Thiago de Souza Carnavale ${ }^{1}$ \\ ${ }^{1}$ CCT, Civil Engineering, Centro Universitário Serra dos Órgãos (UNIFESO), Teresópolis - Brazil
}

\begin{abstract}
The current paper aims to present a comparison between soil-water characteristic curves based on the filter paper method and on a volume-mass estimation. Additionally, this research consists in comparing grain size distributions by sieving/hydrometer and by sieving/Cilas (particle-size analyser model 1092), when it comes to determining the soil-water characteristic curves by a volume-mass prediction on the Soil Vision software. As materials, were used two sets of colluvial soils sampled at the Campus Quinta do Paraiso - Centro Universitário Serra dos Órgãos (UNIFESO), Teresópolis - Brazil. The results showed that the soil-water characteristic curves related to the filter paper method or grain size distribution estimation are different. However, the tests performed by sieving/Cilas are more efficient than the results based on sieving/hydrometer, concerning its uses as input data for soil-water characteristic curves estimations. In conclusion, even considering the estimation method was not able to depict the same results such as obtained by the filter paper method, the use of Cilas is a procedure that can improve the quality of the predicted soilwater characteristic curve.
\end{abstract}

\section{Introduction}

When it comes to analysing unsaturated soils, the knowledge of drying (desorption) and wetting (sorption) processes [1] is considered a key factor for slope stability, flow, soil irrigation, and further analysis.

The effects of the non-saturation can be observed on the hydraulic conductivity [2-4], soil volumetric variation [5,6], and shear strength $[7,8]$ emphasising its remarkable use for geotechnical engineering.

One of the most important approaches is related to the soil-water characteristic curve (SWCC). Since it is assumed [Williams (1982) ccc] as the relationship between water content and suction for a given soil, the SWCC is established by constitutive models [9]. However, the suction of soil under a given water content depends on its history of wetting and drying, and it is difficult to point out.

In order to determine the SWCC, the most common standard test method is based on filter paper [10]. The procedure is related to the suction equilibrium principle, in which two porous materials, when placed in contact, will lose and absorb water until the equilibrium of suction.

Even being a standardised method [11], the filter paper's based procedures have the equilibrium of suction as the major factor responsible for its time-consuming characteristic since its stabilisation time varies according to the level of suction measured and may vary from 7 to 30 days [12-13]. In this way, it is considered a high timeconsuming and because of this; The method is underused in comparison with the benefits it could input in the unsaturated analysis.

Thus, prediction models based on grain-size distributions are revealed as feasible options to obtain the SWCC in a reduced time. An advantage of this technique is that measuring soil grain-size distribution is much more practical and usual than techniques such as the filter paper method. They are easier to perform, and the results are obtained faster as the suction equilibrium time is avoided.

Because of this, the current research is focused on the comparison of a predicted SWCC (based on grain-size distribution - GSD) and the filter paper standard method. Further, it is tested the use of grain-size based on sieving/hydrometer or based on sieving/Cilas particle size analyser as input data for the soil-water characteristic curves estimated by using the Soil Vision software.

\subsection{Theoretical background}

Fredlund et al. (2012) [1] summarised information about developments in the SWCC in soil physics and presented the early equipment and conceptual models of flow in unsaturated soils. Further, it was emphasised that the 
nonlinear soil properties require several tests for the same specimen in order to depict reliable results. One additional obstacle hindering the determination of soilwater characteristic curves is that the same suction might be related to different water content. It happens because the drying path is generally greater than the wetting, showing that there is hysteresis. Thus, it is noteworthy that there are several curves for a given soil, depending on the wetting/drying path.

A vast amount of empirical equations has been proposed to fit experimental data for soil-water characteristic curves (Fredlund, 2012 p.201 [1]). Even though numerous unimodal equations are exposed in the literature, there are an increasing number of equations that reveal a bimodal behaviour in the shape of SWCCs (Qi \& Vanapali, 2015[14]).

The unimodal curves present only one desaturation branch (Figure 1). In the same figure, it is possible to observe the effect of hysteresis since the adsorption is lower than the sorption.

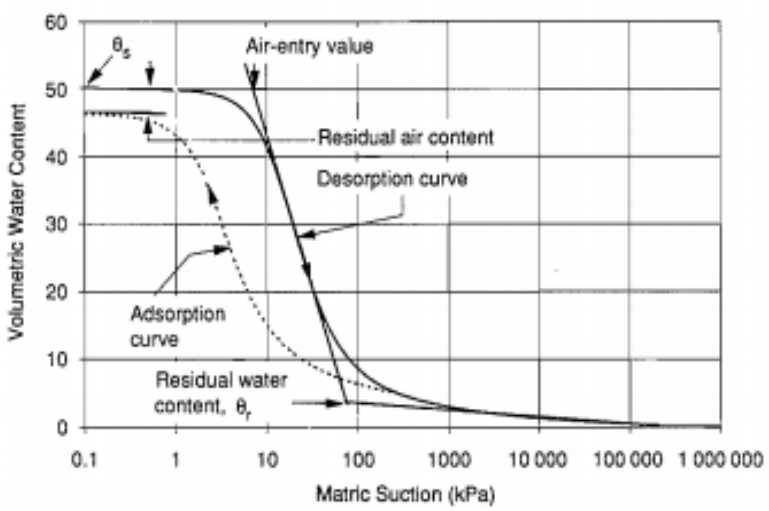

Fig. 1. A typical unimodal SWCC [15].

In the matter of bimodal soil-water characteristic curves, it is composed of two desaturation branches (Figure 2). This type of curve presents two air-entry values (AEVs) related to macro (1st $\mathrm{AEV}$ ) and micropores (2st AEV).

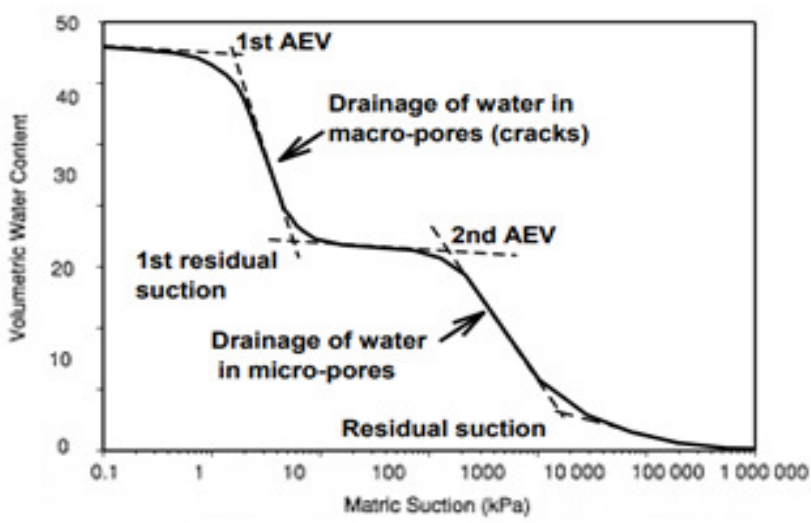

Fig. 2. A typical bimodal SWCC [Adapted from 14].
Besides experimental procedures (here, essentially comprised by filter paper method), indirect pedo-transfer functions (PTFs) [16] have been considered an alternative method when it comes to estimating of the soil-water characteristic curve. A PTF is a function that has its basis on elementary soil data such as the grainsize distribution (Fredlund et al. 2002 [1]). Some of the most useful PTFs are the researches presented by Fredlund \& Wilson PTF (2002) [17] and Arya \& Paris PTF (1981) [18].

\section{Materials}

The colluvial soils used in the tests have been sampled from two depths (Pt $01-25 \mathrm{~cm}$ and Pt $02-75 \mathrm{~cm}$ ) located at Campus Quinta do Paraiso - UNIFESO (geographic coordinates $22^{\circ} 23^{\prime} 35.02^{\prime \prime}$ south and $42^{\circ} 57^{\prime} 40.78^{\prime \prime}$ west).

The sampling point belongs to the Serra dos Órgãos, which is the local description for Serra do Mar. In the geological survey, the area comprises granite (monzogranite) and gneiss rocks. The rocks are constituted by a wide range of minerals such as quartz, muscovite, migmatites [19,20]. Further, regional and local faults are observed as consequence of geomorphological processes.

The soil characterisation was performed according to standard methods NBR-6457 and NBR-6508 [21-22].

Table 1. Physic characterisation of the soils.

\begin{tabular}{|c|c|c|}
\hline Sample & Pt 01 & Pt 02 \\
\hline Specific Gravity & 2.65 & 2.67 \\
\hline $\boldsymbol{\gamma t}\left(\mathbf{k N / \mathbf { m } ^ { 3 } )}\right.$ & 17.5 & 18.5 \\
\hline Liquid Limit (\%) & 47.2 & 54 \\
\hline Plastic Limit (\%) & 35.9 & 27.8 \\
\hline Plasticity Index (\%) & 11.3 & 26.2 \\
\hline
\end{tabular}

Regarding the grain-size distribution, it was accomplished by sieving and hydrometer, such as preconised by NBR-7181 [23]. For the soil classification, was used the Unified Soil Classification System (USCS) [24]. Pt 01: Colluvial, silty-sand (SM); Pt 02: Colluvial, clayey-sand (SC).

\section{Methods}

The method used consists of determining grain-size distribution curves by the standard method and the GSD revealed by the particle size analyser. Afterward, the soil-water characteristic curves were performed based on the filter paper. Additionally, the Soil Vision software was used to fit the GSD according to the experimental values. Further, it was also used to estimate the SWCCs based on grain-size distribution.

\subsection{GSD based on particle-size analyser}


Previously the test execution, the soils were sieved by \#40 and the fine particles were used in the Cilas, model 1190 (Figure 33), with the measurement range between 0.04 and 2,500 microns. The Cilas 1190 is compliant with the ISO 13320 standard for particle size analysers, as well as the $21 \mathrm{CRR}$ part 11 standard.

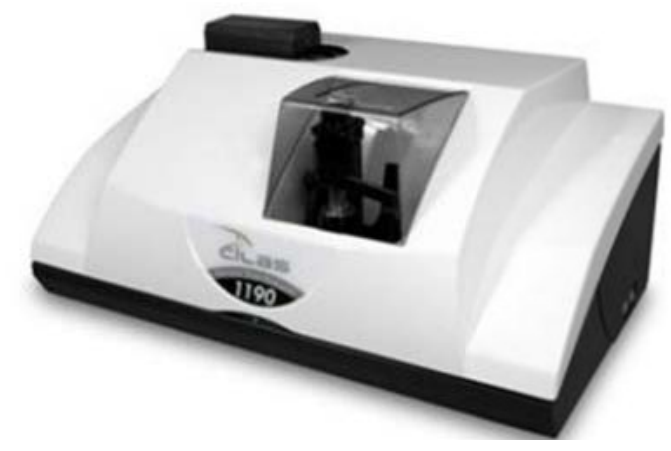

Fig. 3. Cilas 1190 particle size analyser.

\subsection{SWCC based on filter paper method}

The soil-water characteristic curves were determined by the filter paper method. For the test were used 12 samples (Figure 4) for each soil. The moisture/suction intervals were obtained by two branches (sorption and adsorption) and because of this, the effect of hysteresis was not evaluated. Further, there was no volume variation of the soil samples during the procedure.

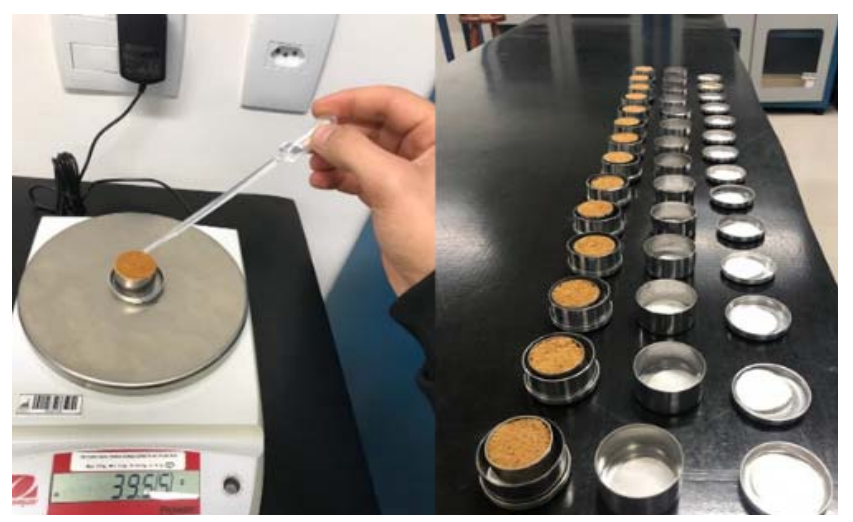

Fig. 4. Filter paper procedure for suction determination.

In order to fit the acquired curve, was used the website http://seki.webmasters.gr.jp/swrc/. Was chosen the method Seki [18] for a bimodal adjust.

\subsection{SWCC based on estimated method}

The estimation of SWCC was carried out by the Soil Vision software. As input data, were used the GSD (standard and Cilas), the specific gravity of the soils, and the saturated gravimetric water content of the soils. Was chosen the Fredlund bimodal fit [17] with an estimation source type coupled to the Ayra and Paris estimation method [18].

\section{Results}

The soil-water characteristic curves presented similar geometries (Figure 5).

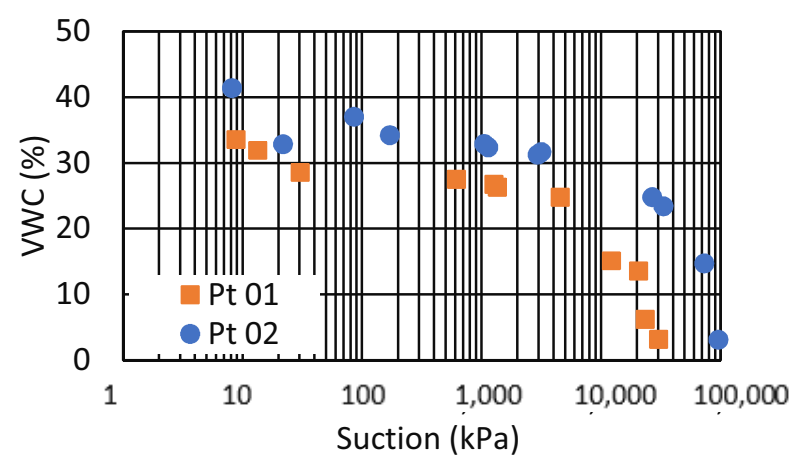

Fig. 5. Soils water characteristic curve.

The fitting method depicted a strong correlation with experimental data, confirming the bimodality of the soils (Figure $6 \mathrm{a}-\mathrm{b}$ ).
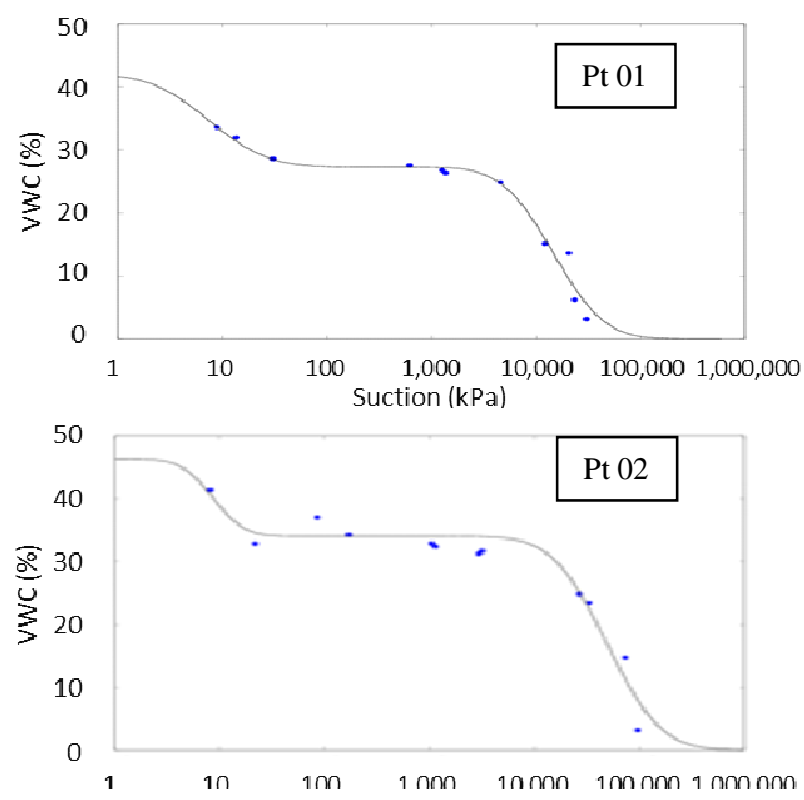

Fig. 6. Soils water characteristic curve fitted.

The grain size distributions performed presented discrepant behaviour concerning the methods carried out (Pt 01 and Pt 02 - standard/Pt 01G and Pt 02G - Cilas coupled).

Due to the hydrometer limitations was not possible to achieve lower values of particle sizes. Due to this, the plot was disrupted around 0,001 mm (Figure 6-a). On the other hand, considering the GSD revealed by the Cilas (coupled to the standard method), it was possible to observe the entire curve (Figure $6-\mathrm{b}$ ).

It is important to emphasise that the particle size analyser just evaluated particles lower than 0,06 mm. Thus, it is possible to observe that the superior branches of the grain size distribution curves were not changed since it only considered the sieving procedure. 

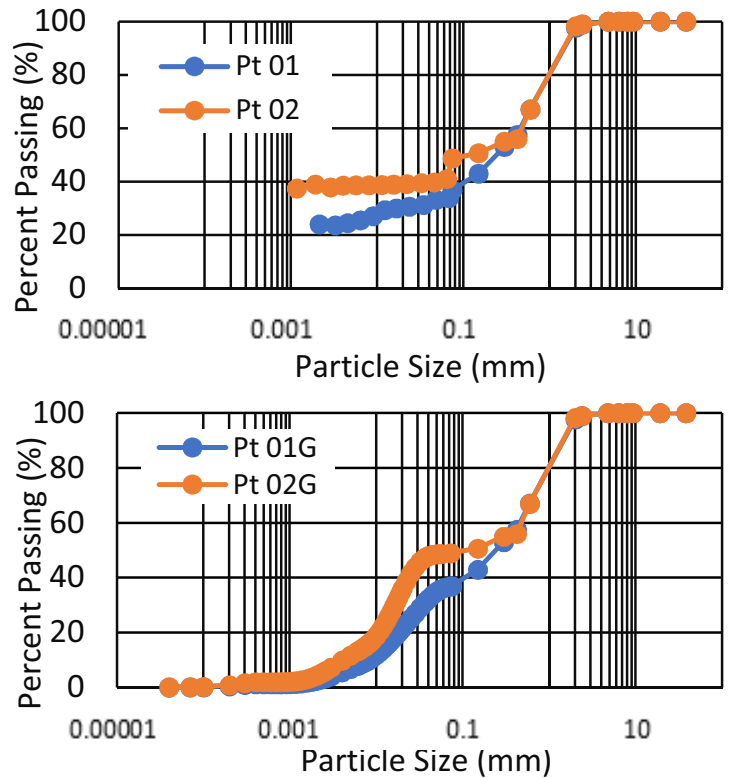

Fig. 6. Standard grain size distributions and method Cilas coupled.

Both grain-size distribution curves were fitted by Soil Vision software. The results (Figure $7 \mathrm{a}-\mathrm{b}$ and Figure 8 $\mathrm{a}-\mathrm{b})$ depict the standard method was better adjusted to Unimodal fiting while Cilas coupled solution (Pt 01G and Pt $02 \mathrm{G}$ ), pointed out a Bimodal behaviour. Further, the $\mathrm{Pt} 02 \mathrm{G}$ presented a noticeable gap-graded. Furthermore, the amount of clay, silt, and fine sand was changed for both soils, affecting the geometry of the curve.
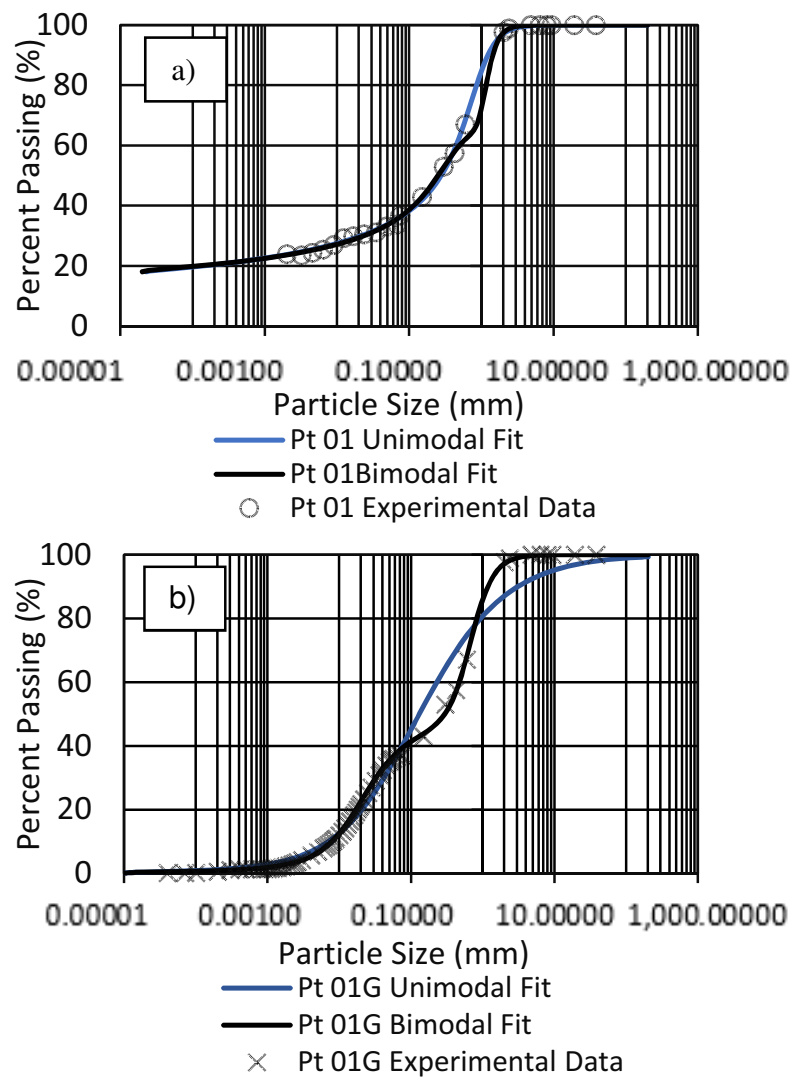

Fig. 7. GSD Fitting - Unimodal and bimodal Pt 01. Standard (a) and Cilas coupled (b). Obtained through the Soil Vision.
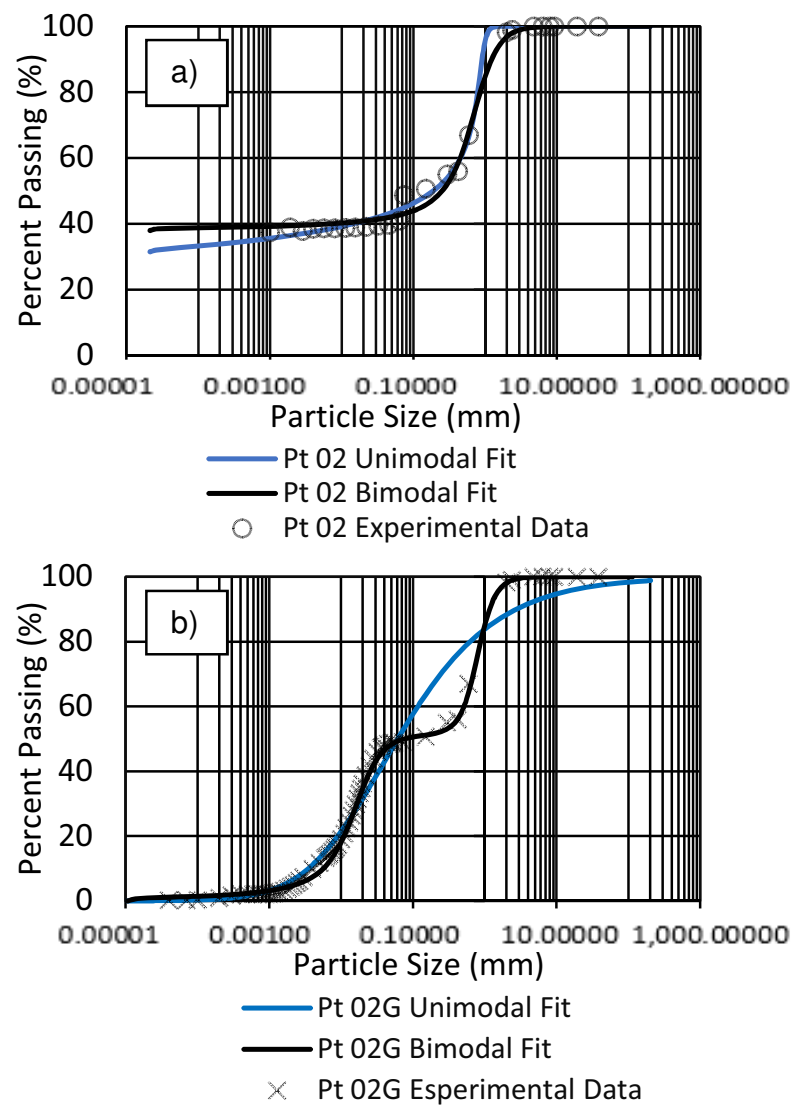

Fig. 8. GSD Fitting - Unimodal and bimodal Pt 02. Standard (a) and Cilas coupled (b). Obtained through the Soil Vision.

The results emphasise the better prediction of the SWCC when is performed with Cilas in comparison with the sieving/hydrometer GSD standard method (Figure 9 b. and Figure 10 b.)

For both soils, the prediction of soil-water characteristic curves related to the grain-size distribution, performed with the standard method, revealed maximum suction values higher than 1.000.000 $\mathrm{kPa}$. It can be considered unreal since the filter paper method reached a maximum of $100.000 \mathrm{kPa}$.

The first air-entry values were different in comparison with the results of the tests based on the filter paper method. According to the bimodal fit, the values should be around $10 \mathrm{kPa}$. In spite of this, were observed values around $100 \mathrm{kPa}$.

Regarding the second air-entry values, related to the micro-pores and to the branch of the grain-size distribution obtained with Cilas, it appeared performed slightly better. However, due to the material composition, the analysis resulted in strong similarities for both soils. 

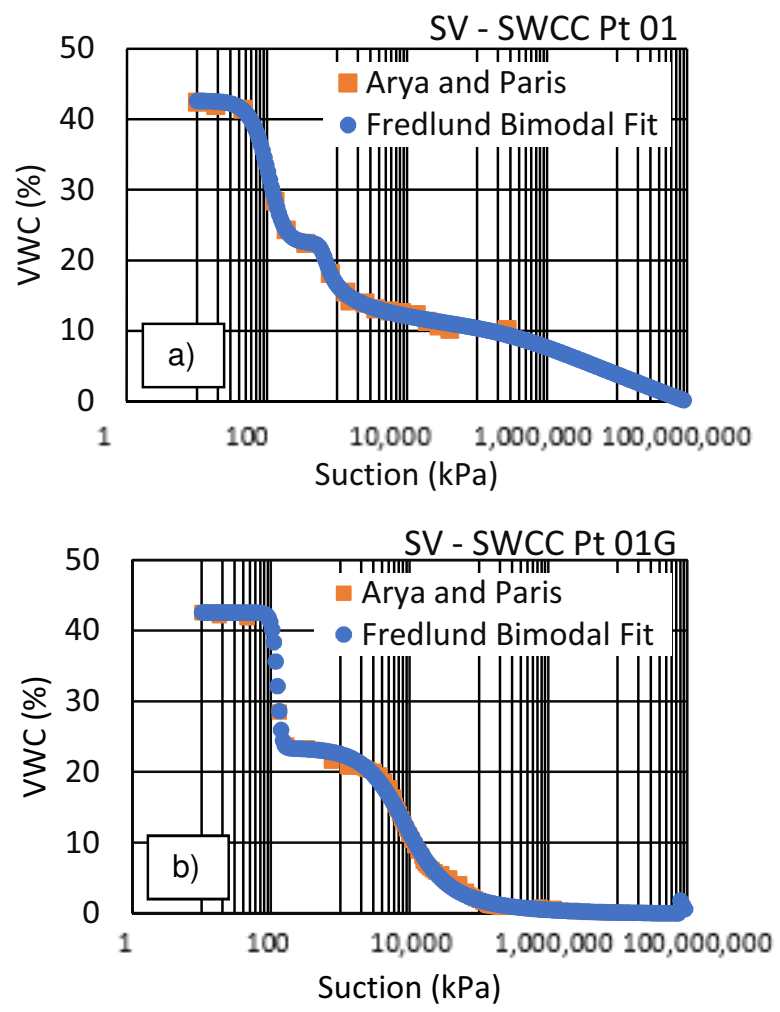

Fig. 9. Fitting - Soils water characteristic curve (Pt 01) using Arya and Paris and Fredlund bimodal fit. Standard GSD (a); Sieving/Cilas (b).
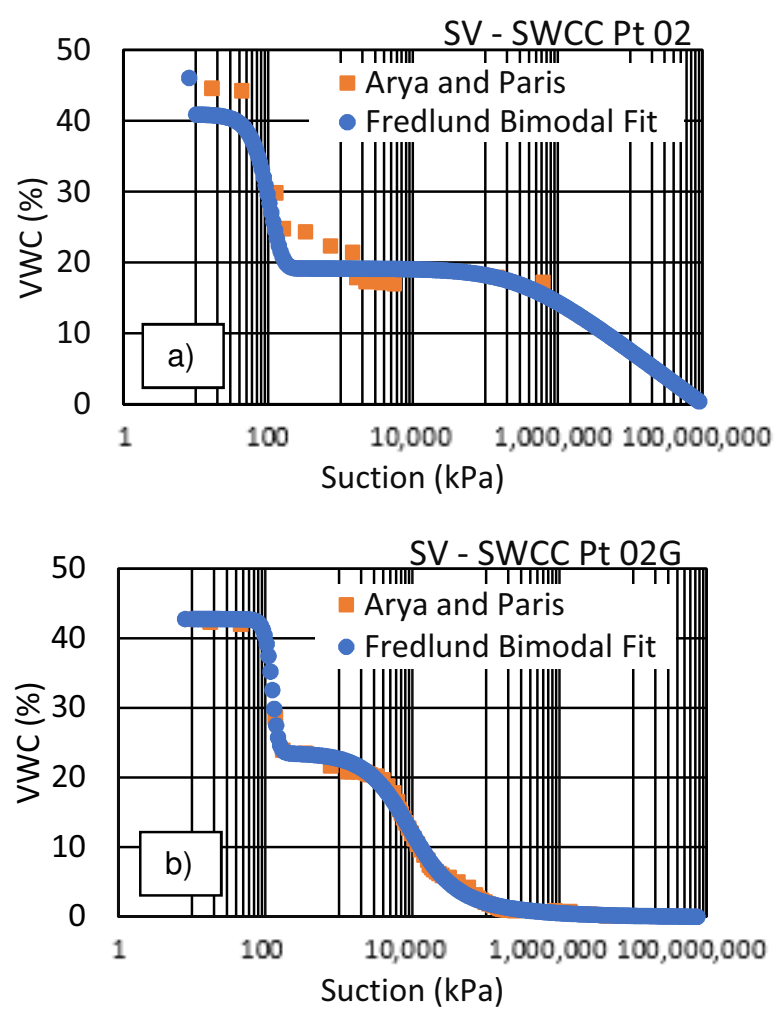

Fig. 10. Fitting - Soils water characteristic curve (Pt 02) using Arya and Paris and Fredlund bimodal fit. Standard GSD (a); Sieving/Cilas (b).

\section{Conclusion}

The grain size distribution revealed a bimodal geometry for the Cilas coupled method, and it was not clear for the GSD results obtained by the standard method. It suggests accordance with (Qi et al. 2009 [14]), in which highlights "there appears to be greater difficulty in estimating the SWCC for silt-clay soils, silt-clay-loam soils, and silt-loam soils for both PTFs, although the predicted SWCCs look similar to the measured results"

In a comparison of Arya-Paris (1981) [17] with Fredlund et al. (2002) [18], pedo-transfer functions, the solution based on Fredlund et al. (2002) [1] PTF performed slightly better than the Arya-Paris (1981) PTF for both soils.

Finally, Cilas particle-size analyser provides a better knowledge of the particle-size distribution of the soils, contributing to generate refined soil-water characteristic curves by using the prediction method on Soil Vision software.

\section{Acknowledgements}

This research was financed by UNIFESO. We would like to thank the staff of the laboratory Thiago Piantino da Camara for his uncountable dedication. Also, we are thanked PUC-Rio and Professor Tácio M. P. de Campos for the use of Cilas.

\section{References}

1. Fredlung, D.G.; Rahardjo, H.; Fredlund, M.D. Unsaturated soil mechanics for engineering practice. John Wiley \& Sons, Inc, 926 p (2012)

2. Mualem, Y. Water Resources Research, Vol. 12, pp. 513-522. (1976)

3. van Genuchten, M. T. Soil Science Society of America Journal, 44, pp892-898 (1980)

4. Wang DL, Luan MT and Yang Q. Journal of Disaster Prevention and Mitigation Engineering. 27(3): 307-311. (2007)

5. Fredlund, D. G., \& Houston, S. In Advances in Unsaturated Soils - Proceedings of the 1st PanAmerican Conference on Unsaturated Soils, PanAmUNSAT 2013 (pp. 15-31) (2013)

6. Fredlund DG, Xing A, Fredlund MD, Barbour SL. Canadian Geotechnical Journal. 32: 440-448. (1995)

7. Vanapalli, Sai \& Fredlund, D.G. \& Pufahl, D.E. \& Clifton, A.W. Canadian Geotechnical Journal, 33. 379-392. 10.1139/t96-060. (1996)

8. Fernando Flávio Marques de Almeida, Benjamim Bley de Brito Neves, Celso Dal Ré Carneiro. Publication: Earth-Science Reviews. Publisher: Elsevier. (2000).

9. E. C. Leong and H. Rahardjo. Journal of Geotechnical and Geoenvironmental Engineering, vol. 123(12), pp. 1106-1117 (1997) 
10. rooks, R.H. and Corey, A.T. Hydraulic Properties of Porous Media. Hydrology Papers 3, Colorado State University, Fort Collins, 27 p. (1964)

11. Rodrigues, Juliana \& Tupinambá, Miguel \& Amaral, Claudio. Anuario do Instituto de Geociencias. $35 . \quad 152-164$. 10.11137/2012_2_152_164.(2012)

12. ASTM D5298-03. ASTM International, West Conshohocken, PA, (2003)

13. K. Bicalho; A. Correia; S. Ferreira; J-M, Fleureau; F. Marinho. Filter paper method of soil suction measurement. (2007)

14. Marinho, F. A. M.; Oliveira, O. M. Geotechnical Testing Journal, v. 29, n. 3, p. 1-9, (2006)

15. Qi, Shunchao \& Vanapalli, Sai. Numerical study on expansive soil slope stability considering the effect of swelling behaviour and cracks. 10.13140/RG.2.2.19096.49927. (2015)

16. Fredlund, D.G. and Xing, A. Canadian Geotechnical Journal, 31(3): 521-532. (1994)

17. Huang, Mingbin \& Fredlund, bullet \& Fredlund, bullet \& Fredlund, D \& Fredlund, Murray. Eng, Geotech. J. 39. 1103-1117. 10.1007/s10706-0099284-X. (2002)

18. Fredlund, M.D., Wilson, G.W. and Fredlund, D.G. Canadian Geotechnical Journal, 39, pp1103-1117. (2002)

19. Arya, L.M. and Paris, J.F. Soil Sci. Soc. Am. J. 45(6): 1023-1030. (1981)

20. DRM-RJ. Rio de Janeiro. p.18-89. http://www.drm.rj.gov.br/index.php/downloads/cat egory/13-regio-serrana.html (2011) (in portuguese)

21. L. Lago; C. Amaral; L. E. P. Campo; L. E. Silva. MEGADESASTRE '11 In: Simpósio de Geologia do Sudeste, 12, Nova Friburgo, RJ. (2011) (in portuguese)

22. ABNT - Associação Brasileira de Normas Técnicas. NBR-6457: Rio de Janeiro. (1986)

23. ABNT - Associação Brasileira de Normas Técnicas. NBR-6508. Rio de Janeiro. (1984)

24. ABNT - Associação Brasileira de Normas Técnicas. NBR-7181. Rio de Janeiro. (1984a)

25. Howard, Amster K. Soil Geotechnical Branch, Division of Research and Laboratory Services, Engineering and Research Center, Bureau of Reclamation, (1986) 